\title{
A STUDY OF THE EFFECT OF HUNGER ON NERVOUS IRRITABILITY *
}

\author{
JESSE R. GERSTLEY, M.D., AND R. G. HOSKINS, M.D. \\ CHICAGO
}

During a summer vacation one of us (R. G. H.) observed that a fat, lazy, overfed dog, after having been lost for three days, returned thinner, brighter and more alert and active in every way. At this time A. J. Carlson in his work on the physiology of hunger suggested that gastric contractions were associated with some increase in general nervous irritability. Zybell's ${ }^{1}$ clinical studies on spasmophilia also have a bearing on this subject. He concluded that any prolonged hunger aggravates the condition. He cast doubt on the idea that spasmophilia might be attributed to any specific element in the milk mixture, as the whey, the carbohydrate, or the starch additions, and demonstrated that independent of the nature of the food, a period of hunger prolonged over a few hours made the child decidedly worse. Indeed, he went even farther by showing that in spasmophilia the electrical reactions vary sometimes 1 to 2 milliamperes from morning to evening. These differences are due to the effect of hunger. The child, going through the night with very little food, awakens in the morning with pathologic reactions. After the day's feeding electrical irritability becomes normal. By changing the routine, by feeding through the night and giving very little food during the day, Zybell was able to reverse the reaction.

From these studies and observations one is tempted to advance the hypothesis that there is a general law in nature making increased nervous irritability coincident with increased hunger. If this were so, it could possibly be demonstrated in mathematical form by means of the electric current. This we attempted. Our first work was with infants, but the tendency of the electrodes to burn the skin, the restlessness of the children making accurate readings difficult, and our own reluctance to subject the children to any prolonged starvation, led us to transfer the work to dogs.

Perhaps the most extensive researches in animals on the subject of electrical excitability are those of Noel Paton ${ }^{2}$ and his associates. These observers, in the course of their work on parathyroid tetany, demonstrated $(a)$ the extreme variability of the reactions, and $(b)$ the sensitizing effect of the current, namely, that a nerve after once

* Submitted for publication Jan. 15, 1918.

* From the Departments of Pediatrics and Physiology of the Northwestern University Medical School, and the Sarah Morris Hospital for Children.

1. Zybell: Jahrb. f. Kinderh., 1913, 28, 29.

2. Paton, N.: Quart. Jour. Exper. Physiol., 1916, 10, 203. 
reacting becomes sensitized, and then reacts to about one-half to onequarter of the primary stimulus.

The problem which we thought could easily be settled in a few weeks lengthened to almost two years. During this time we learned much about electrical reactions, particularly the difficulty of obtaining any sort of definite standard. In a normal dog, even at best, the reactions show extreme variability, changing not only day by day, but sometimes almost minute by minute. During moist days the atmosphere seemed to induce currents in the electrical machine; on other days small deflections in the needle could be traced to the iron work in the building, electrically charged for some unknown reason. To hold animals quiet for any length of time is difficult, and one is often

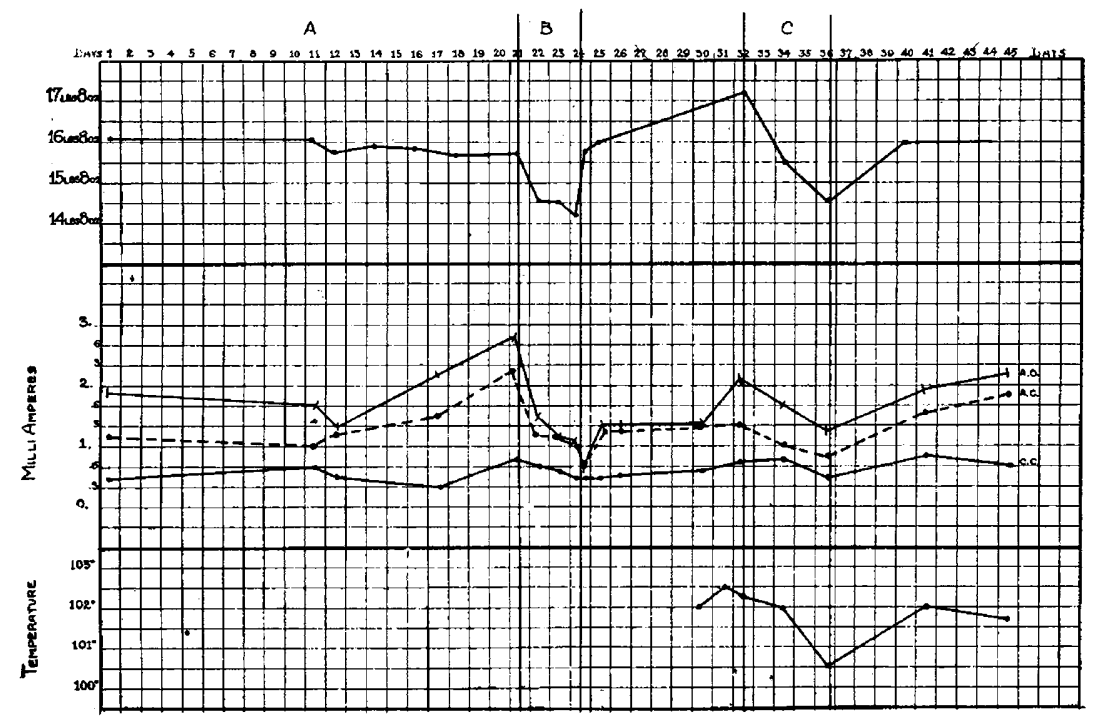

Period A, change of hygiene of kennels; Period B, three days' starvation; Period C, four days' starvation. AO, anode opening; $\mathrm{AC}$, anode closing; $\mathrm{CC}$, cathode closing. The readings were all taken in the morning, except on the twenty-fourth day when a. m. and p. m. observations were made.

confused as to whether the muscular contraction is due to the current, to shivering, or is voluntary. Then again, dogs vary in temperament, some being exceedingly nervous, irritable and timid, while others are calm and make quiet subjects. Due to these many and often uncontrollable variables, we threw out repeatedly whole series of observations; at times we even despaired of obtaining any definite result. A few experiments were carried out successfully, however, and the accompanying curve may be taken as illustrative of some of the series.

The technic of these experiments was that ordinarily employed in obtaining the reactions in children. In order to be sure that the animals were experiencing the true hunger effects, we controlled their weight and temperature. 


\section{DISCUSSION}

In studying the chart, particularly AOC, which observers have found the most constant, one finds some increase in the electrical excitability during the hunger periods, but we have learned of so many variables, and have ploted so many curves which do not show this increase, that we do not feel justified in asserting this as a definite law. That there is no direct parallelism between electrical excitability and duration of the hunger period, or between the former and the weight curve, however, is certainly shown by the p.m. reading of the twenty-fourth day. Here the animals had been on a full diet for six hours; the weight curve took a sharp rise, but the curve of electrical excitability went down. At no time, in spite of the severity of the hunger and the drop of weight, did starvation bring $\mathrm{COC}$ anywhere near 5 milliamperes. Thus we believe hunger to be of no great practical importance in predisposing a normal individual to spasmophilia. We believe the general subject of hygiene to be more important. During the first few days the dogs were confined in dark, unpleasant kennels; their appetites were poor and they were unhappy. At A they were placed in pleasanter quarters, were allowed freedom, fresh air, exercise and sunshine. It will be seen that during the period $\mathrm{C}$, after four days' starvation, the reactions are barely lower than in the prestarvation, poor hygiene days.

\section{CONCLUSIONS}

We were not able by means of the electric current to demonstrate in all cases a constant parallelism between the length of the hunger and the degree of electrical irritability. This latter seems to be influenced more by general hygiene, conditions of the kennels, exercise, sunshine, appetite and body weight than by the hunger factor alone. Perhaps the parallelism may be demonstrated by psychoanalytical methods. We certainly can confirm the work of Noel Paton and his associates as to the extreme variability of these reactions and the sensitizing effect of the electric current. This latter observation may be of clinical value. One should never be satisfied with a first reading. The observation should be repeated several times; often a contraction will be obtained by one half to one fourth the original stimulus. The failure of the COC even after four days' hunger nearly to approach 5 milliamperes leads us to conclude that hunger can scarcely be a factor in predisposing normal individuals to spasmophilia.

We wish to express our thanks to Dr. O. T. Schultz for the privileges of the laboratories of the Nelson Morris Memorial Institute, and to Mr. E. L. Berry of Northwestern University Medical School for his technical assistance.

4325 Michigan Avenue. 